See discussions, stats, and author profiles for this publication at: https://www.researchgate.net/publication/317731341

\title{
Development and testing of low spatial frequency holographic concentrator elements for collection of solar energy
}

Article in Solar Energy · October 2017

Dol: $10.1016 /$ j.solener.2017.04.067

CITATIONS

15

5 authors, including:

(2)

oda Akbari

Trinity College Dublin

14 PUBLICATIONS 201 CITATIONS

SEE PROFILE

Hind Ahmed

Trinity College Dublin

52 PUBLICATIONS 359 CITATIONS

SEE PROFILE

Some of the authors of this publication are also working on these related projects:

Barriers to RES uptake View project

"Photopolymer nanocomposites for development of holographic microactuators" View project
Izabela Naydenova

Technological University Dublin - City Campus

169 PUBLICATIONS 2,495 CITATIONS

SEE PROFILE

A. S.J.McCormack

Trinity College Dublin

171 PUBLICATIONS 4,321 CITATIONS

SEE PROFILE 


\title{
Development and testing of low spatial frequency holographic concentrator elements for collection of solar energy
}

\author{
Hoda Akbari ${ }^{a}$, Izabela Naydenova ${ }^{a}$, Hind Ahmed ${ }^{\mathrm{b}}$, Sarah McCormack ${ }^{\mathrm{c}}$, Suzanne Martin ${ }^{\mathrm{a}, *}$ \\ ${ }^{a}$ Centre for Industrial and Engineering Optics, School of Physics, Dublin Institute of Technology, Kevin Street, Dublin 8, Ireland \\ ${ }^{\mathrm{b}}$ Dublin Energy Lab, School of Physics, Dublin Institute of Technology, Kevin Street, Dublin 8, Ireland \\ ${ }^{\mathrm{c}}$ Department of Civil, Structural and Environmental Engineering, Trinity College, Dublin 2, Ireland
}

\section{A R T I C L E I N F O}

\section{Article history:}

Received 23 December 2016

Received in revised form 28 March 2017

Accepted 27 April 2017

\section{Keywords:}

Acrylamide based photopolymer

Transmission gratings

Low spatial frequency

Diffractive optical elements

Polarization

Holographic concentrators

Crystalline Silicon (c-Si) solar cells

\begin{abstract}
A B S T R A C T
The aim of this research is to use holographically recorded diffractive optical elements (DOEs) recorded in photopolymer in order to effectively collect and concentrate solar radiation. The potential for recording high diffraction efficiency DOEs with a large angular and wavelength range of operation in acrylamide based photopolymer and the optimum recording conditions have been presented in our previous work (Akbari et al., 2014b, 2014a). Theoretical modelling and experimental test are presented which demonstrate that low spatial frequency components, around 300 line pairs $/ \mathrm{mm}$, have an appropriate spectral bandwidth, high efficiency and very limited polarization dependence. Pairs of concentrating off-axis lenses are fabricated in photopolymer and arranged to concentrate light on a c-Si cell. The optical recording process is described and discussed. The results from electrical characterization confirm that with the (two) spherical DOEs (each of area $113 \mathrm{~mm}^{2}$ ) in place, the output current of c-Si solar cells is approximately doubled for the solar cells with area of $12 \mathrm{~mm}^{2}$.
\end{abstract}

(c) 2017 Published by Elsevier Ltd.

\section{Introduction}

There are a number of approaches to improving the efficiency of photovoltaic (PV) systems. Concentrating solar energy onto a PV material reduces cell area per unit electrical output and, for certain cell materials and designs, increases PV conversion efficiency (Rabl, 1976). This enables the total system cost to be reduced per unit of energy delivered, (Winston and Hinterberger, 1975; Kennedy et al., 2009; Norton et al., 2011; Wisam et al., 2016; Kabeel and Abdelgaied, 2017). Solar concentration is usually undertaken by imaging optics refractively using lens (Xie et al., 2011; Xu et al., 2016) or reflectively using mirrors (Arancibia-Bulnes et al., 2017) or non-imaging optics (using compound parabolic concentrators (Eames and Norton, 1977; Mallick et al., 2015; Singh and Tiwari, 2017), or luminescent solar concentration, (Goetzberger and Greubel, 1977; Reisfeld et al., 1988; Barnham et al., 2000; Gallagher et al., 2007; Chandra et al., 2015). The limitations of each are mainly determined by concentration ratio required and cost, where imaging optics can achieve much higher concentration of direct radiation to intensities greater than 1000 suns, and non imaging concentrators such as CPCs have much lower concentration ratios but they have wider acceptance angles.

\footnotetext{
* Corresponding author.

E-mail address: Suzanne.martin@dit.ie (S. Martin).
}

In this paper we investigate a diffractive solar concentrator which also collects solar radiation over a large area and redirects it onto a smaller area, where it can be converted for example into electrical energy using PV cells. Holographically recorded diffractive optical elements (DOE) are investigated for use in the collection of solar radiation from a moving source, such as the sun, and its redirection onto a fixed detector/convertor for solar concentrator applications.

Holographically recorded volume Diffractive Optical Elements (DOEs) have potential as solar concentrators because of their ability to diffract light at large offset angle, and the potential for multiplexing a number of optical components in the same layer. Recent research has demonstrated different diffractive elements in a variety of arrangements for solar applications that will re-direct and focus incoming light to the desired 'line' or 'spot' for conversion (Bañares-Palacios et al., 2015; Castro et al., 2010; Ghosh et al., 2015; Hsieh et al., 2011; Hung et al., 2010; James and Bahaj, 2005; Kostuk et al., 2011; Kostuk and Rosenberg, 2008; Sam et al., 2011; Shakher and Yadav, 2000).

A number of researchers have demonstrated novel designs over the years (Sreebha et al., 2015; Belendez et al., 1991; Breitenbach and Rosenfeld, 2000; Mohan and Islam, 2006). For example Sreebha et al., 2015, have reported results on the recording of transmission holographic optical elements in a silver halide material. The wavelength selectivity and focusing properties of the 
recorded holographic lens was used to design a concentrator for dye sensitized solar cells. The fabricated holographic lens was reported to achieve $32.9 \%$ energy enhancement with the HOE in place while the dye cells were collecting the yellow radiation of the solar simulator light source.

Breitenbach and Rosenfeld (2000) investigated the optical properties of thin HOEs. The spatial and spectral distributions of light transmitted by the HOE were measured for a range of wavelengths between 300 and $2100 \mathrm{~nm}$ and for various angles of incidence. The results demonstrate the capability of HOEs to separate the visible light from the infrared part of solar spectrum. This can be very beneficial in solar applications since daylighting and the solar gain can be controlled individually.

The design of multi-channel HOE has been demonstrated by Mohan and Islam (2006). A range of HOEs were recorded in silver halide recording material using five reference beams in order to concentrate light at a range of incident angles. The maximum efficiency of $15 \%$ was achieved for a HOE with the dimensions of $58 \mathrm{~mm} \times 58 \mathrm{~mm}$ over an angle-span of $12^{\circ}$. HOEs were recorded by using five reference beams.

A planar concentrator using a low-cost holographic film that selects the most useful bands of the solar spectrum and concentrates them onto the surface of the photovoltaic cell has been demonstrated by Kostuk et al. (2007). The holographic elements have been implemented in 5-25 $\mu \mathrm{m}$ thick layers of dichromated gelatin (DCG). The result show a $25 \%$ increase in the output from the cell over the output without the holographic element. However, it can be assumed that stacking multiple gratings or multiplexing several gratings in the same volume could significantly improve the module efficiency.

Photopolymers are excellent materials for producing similar diffractive elements, being thin, lightweight, inexpensive and highly efficient, but challenges remain in reducing the angular selectivity of these relatively thick layers and in applying the technology to natural light in real-world applications. High efficiency diffractive optical elements have been recorded in photopolymer material previously for this and other applications (Fernández et al., 2008; Fimia et al., 1994; Gallego et al., 2008; Gleeson et al., 2008; Guntaka et al., 2002; Jenney, 1970; Martin et al., 1998; Srivastava et al., 2012; Tarjányi et al., 2009). Multiplexing of thick transmission holograms in photopolymer has also been investigated. For example, Naydenova et al. (2013) reported on recording multiplexed cylindrical holographic lenses with high diffraction efficiency in order to direct the light in a fixed direction independently of the direction of incoming light. Bianco et al. (2015), reported on recording an array of three spherical lenses in a solgel photopolymer which can be used as solar concentrator.

Altmeyer et al. (2013) demonstrated the potential of multiplexing of thick transmission holograms in photopolymer. The variation of the diffraction efficiency of the multiplexed grating with respect to the angle of incidence and the wavelength are theoretically shown. The experimental results of the angular acceptance of the single and four multiplexed holograms are compared with the simulation results. A maximum diffraction efficiency of $60 \%$ was achieved for a layer with thickness $16 \mu \mathrm{m}$. This demonstrates the potential for recording multiple high efficiency elements simultaneously in photopolymer layers. However further work is required to design combinations of elements that direct the light in single direction in order to make it useful for solar applications.

Thick transmission holograms and diffraction gratings recorded in acrylamide based photopolymer can be used to change the direction of a light beam with greater than $90 \%$ efficiency but are generally only efficient over a small range of angles close to the Bragg angle. Previous work by the authors addressed the issue of increasing the angular working range in photopolymers and demonstrated photopolymer spherical and cylindrical focussing elements that had very high efficiency when measured with monochromatic, linearly polarized laser sources (Akbari et al., 2014a, 2014b). The aim of this work is to test cylindrical and spherical focusing diffractive elements using an unpolarised broadband source, and also to fabricate and test combinations of pairs of elements designed to direct and focus this light onto the same solar cell. Silicon cells are used as the convertor. The relative increase of the output current of c-Si solar cells using the DOEs is investigated using a solar simulator.

\section{Materials and methods}

\subsection{Photopolymer solution preparation}

The composition of the acrylamide-based photopolymer used in this study consists of two monomers (Acrylamide and NN'methyle nebisacrylamide), an electron donor (Triethanolamine), a dye sensitizer (Erythrosine B, sensitive to light of $532 \mathrm{~nm}$ wavelength) and a binder (Polyvinylalcohol) which keeps all of the components suspended. The solutions were mixing for $90 \mathrm{~min}$ to ensure that the monomers are completely dissolved The thickness of the layer was $50 \pm 5 \mu \mathrm{m}$ thick, as measured by white light interferometry.

\subsection{Layer preparation}

$0.5 \mathrm{ml}$ of the photopolymer solution was spread evenly using the gravity settling method on a $26 \times 76 \mathrm{~mm}^{2}$ glass substrate and then placed on a levelled surface and allowed to dry for 18$24 \mathrm{~h}$ in darkness with temperature and relative humidity ranging between $20-25^{\circ} \mathrm{C}$ and $40-60 \% \mathrm{RH}$.

\subsection{Experimental set-up}

\subsubsection{Holographic set-up for recording DOEs}

In this report, DOEs were recorded using a $532 \mathrm{~nm} \mathrm{Nd: \textrm {YVO } _ { 4 }}$ laser and a Helium-Neon laser (He-Ne) at $633 \mathrm{~nm}$ was used as a probe beam. The recording set up is shown in Fig. 1. The S polarized beam was split in two via a non-polarizing beam splitter and recombined at the photopolymer plate using reflection at a plane mirror. The inter-beam angle was set at $9.14^{\circ}$ in air in order to produce gratings with a central spatial frequency of $300 \pm 30$ line pairs $/ \mathrm{mm}$. The exposure time was kept constant at $60 \mathrm{~s}$, thus exposure energy of $60 \mathrm{~mJ} / \mathrm{cm}^{2}$ in a layer of thickness $50 \pm 5 \mu \mathrm{m}$ was achieved. Optical lenses with a range of focal lengths $(3-10 \mathrm{~cm})$ were placed in the object beam. In order to maximize the aperture of recorded HOE, it was essential that the object beam and the ref-

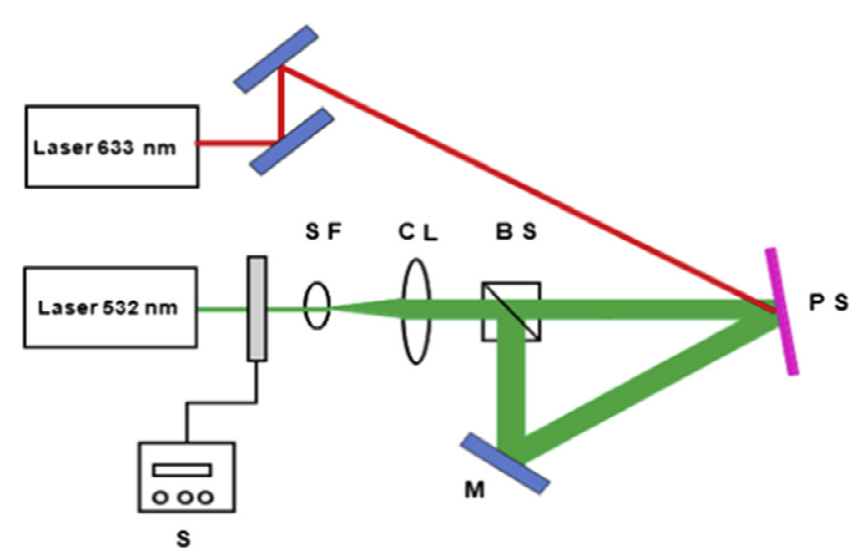

Fig. 1. Experimental set up: S: shutter, $C L$ : collimating lens, BS: beam splitter, SF: spatial filter, M: mirror, PS: photopolymer sample. 
erence beam fully overlapped at the photosensitive layer. The recording geometry is shown in Fig. 2(a).

\subsubsection{Holographic set-up for testing DOEs using laser light}

The absorption of this formulation of the photopolymer at $633 \mathrm{~nm}$ is negligible even before exposure; therefore, a $633 \mathrm{~nm}$ He-Ne laser was used as a probe beam to characterize the diffracted efficiency dependence on the incident angle of the probe beam. The reconstruction geometry is shown in Fig. 2(b). Except where otherwise stated, the probe beam was linearly polarized in the plane perpendicular to the optical table (plane of incidence) i.e. S polarized light. A rotation stage (Newport, ESP 300) was used to vary the angle of the probe beam with respect to the recorded DOE. An optical power meter (Newport 1830-C) recorded the intensity of the diffracted beam and the data was transferred to a computer via a data acquisition card. A LabVIEW program was used to control the experiment and to record the data. The diffraction efficiency, $\eta$, of the recorded grating was defined as the ratio of the intensity of the first diffraction order and the intensity of the probe beam. The diffraction efficiency of each focusing DOE was determined by measuring the diffracted beam's intensity close to the focal point. For the studies of the dependence of the diffraction efficiency on the state of polarization of the probe beam the laser was rotated by $90^{\circ}$ i.e. $P$ polarized light was used instead of the $S$ polarized light. Fig. 2 shows the ray diagram for (a) recording (b) reconstruction beam angles inside the recording medium. In Fig. 2, $\theta_{1}$ and $\theta_{2}$ are the angles of incidence of the two recording beams where $\theta_{1}^{\prime}$ and $\theta_{2}^{\prime}$ are the refraction angles inside the photosensitive material according to Snell's law. Angle $\theta_{\mathrm{B}}$ is the angle between the incident beam and the grating fringes, angle $\phi$ is the angle between grating fringes and the normal and $\Lambda$ is the grating period.

\subsubsection{Electrical characterization with solar simulator light source}

The electrical characterization was carried out by measuring the Current-Voltage (I-V) characteristics of c-Si solar cells (Solar capture technologies) with and without the DOE placed in front of the cell in such a way as to re-direct and focus additional light onto the solar cell.

I-V curve of the solar cell represents the output current Vs output voltage at which the solar cell is operating when the condition of irradiation $\left(1000 \mathrm{~W} / \mathrm{m}^{2}\right)$ and temperature $\left(25^{\circ} \mathrm{C}\right)$ were held constant. Five I-V measurements were taken for each device test and the results were averaged. The standard deviation between measurements was within $3 \%$.

I-V measurements were performed with a Keithley 2400 SMU (Source Meter Unit) with a Labview interface, using a set up shown in Fig. 3. Two DOEs were recorded on the left and right of a glass plate so as to gather additional light and deflect it onto the solar cell. Their position and focal length were chosen so as to ensure overlap of the beams at the solar cell location, as shown in Fig. 3. The light source used was a metal halide discharge lamp (Griven, GR0262).

The individual current and voltage output from each solar cell is read by a data acquisition card (DAQ). The measured current and voltage values were acquired by a computer programme written in NI Labview.

It was important to align the DOE so that the diffracted beam was directed onto the solar cell since the recorded DOEs are offaxis elements. The distance between the DOE and the silicon cells was the same as the focal length of the DOEs which in this case was $5 \mathrm{~cm} \pm 0.1 \mathrm{~cm}$. This arrangement tests the effect of two DOE elements; however, the final application would involve larger number of arrays of such elements surrounding the cell, each contributing additional light.

\section{Results}

\subsection{Recording high efficiency diffractive optical elements at low spatial frequency}

The DOEs were made by interfering a focussed by a cylindrical lens beam with a reference beam (collimated) and arranging the photopolymer layer at the area of overlap as described in Section 2.3.1. Since the spatial frequency of the grating planes will vary across the DOEs, the maximum and minimum spatial frequency was calculated using the geometry of the experimental set up, and was found that the spatial frequency ranges between 112 line pairs $/ \mathrm{mm}$ - 485 line pairs $/ \mathrm{mm}$ can be achieved in each grating.

A range of DOEs with an off-axis focusing effect were recorded in order to demonstrate focusing elements with low spatial frequency, extended working angular and wavelength range and minimal sensitivity to the polarization state of the source. The variation of diffraction efficiency with angle of incidence for a recorded cylindrical and spherical DOE with central spatial frequency of 300 line pairs/mm with thickness $50 \pm 5 \mu \mathrm{m}$ is shown in Fig. 4. The results are compared with the theoretical result which is presented in a solid line. These gratings are thick, volume phase gratings with very small slant angles, so Kogelnik's Coupled Wave Theory can be successfully used to model the diffraction behavior. For accurate comparison, the probe beam was placed in the centre of the gratings throughout the measurements. The experimental FWHM of the cylindrical and spherical DOE are $3.0 \pm 0.1^{\circ}$ and $4.0 \pm 0.1^{\circ}$ respectively, demonstrating an angular range of operation that is large in comparison to other DOEs

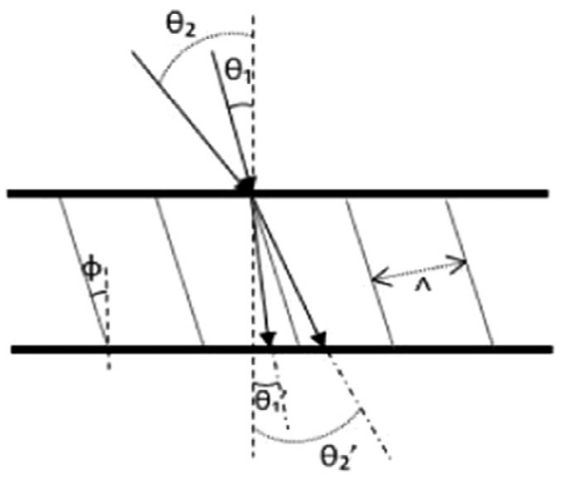

(a)

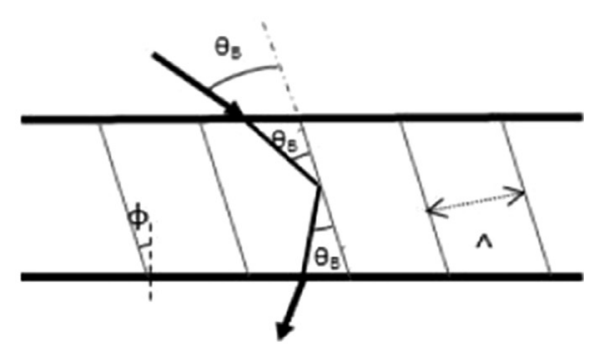

(b)

Fig. 2. Geometry of (a) recording and (b) reconstruction of diffractive optical elements. 


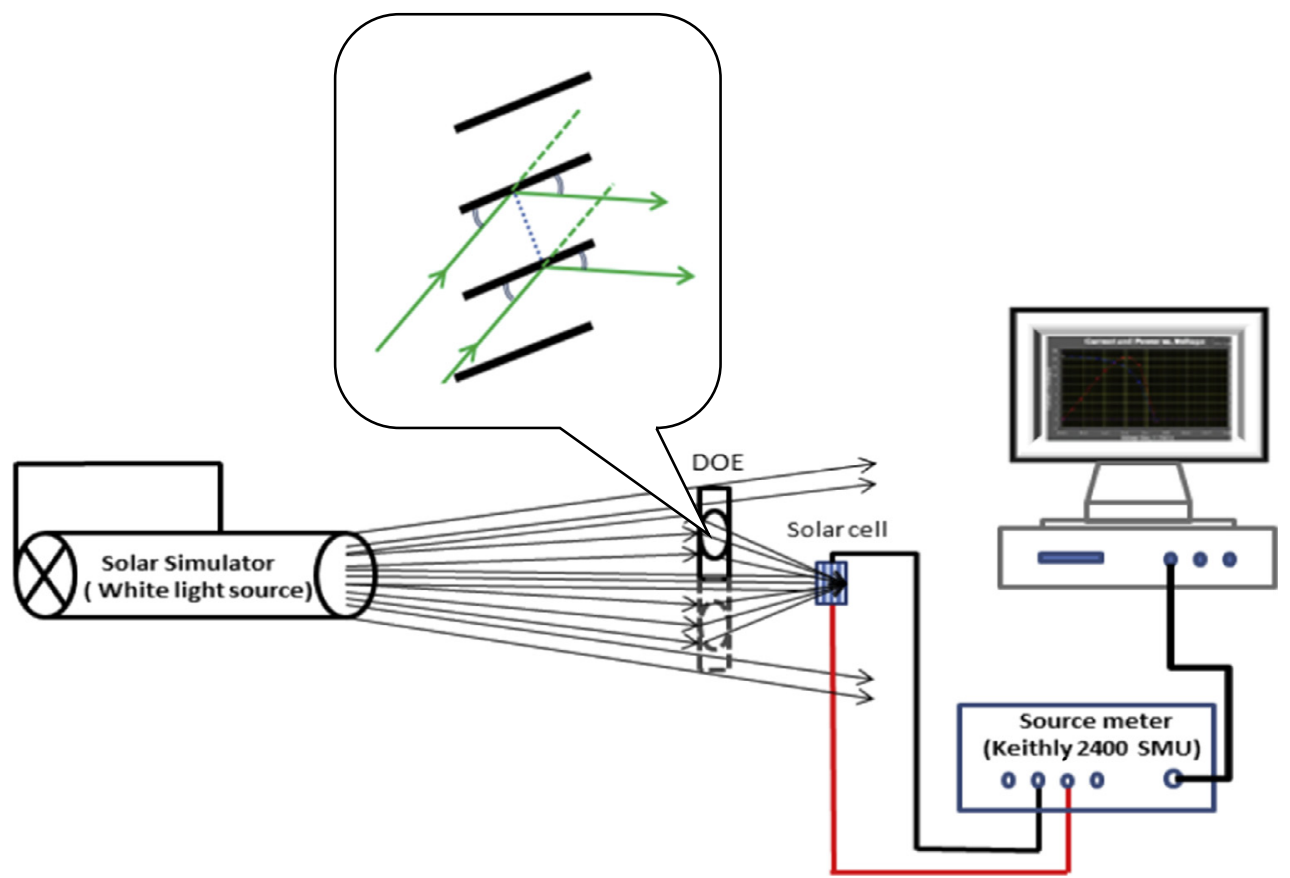

Fig. 3. Diagram of the experimental setup for electrical measurements.
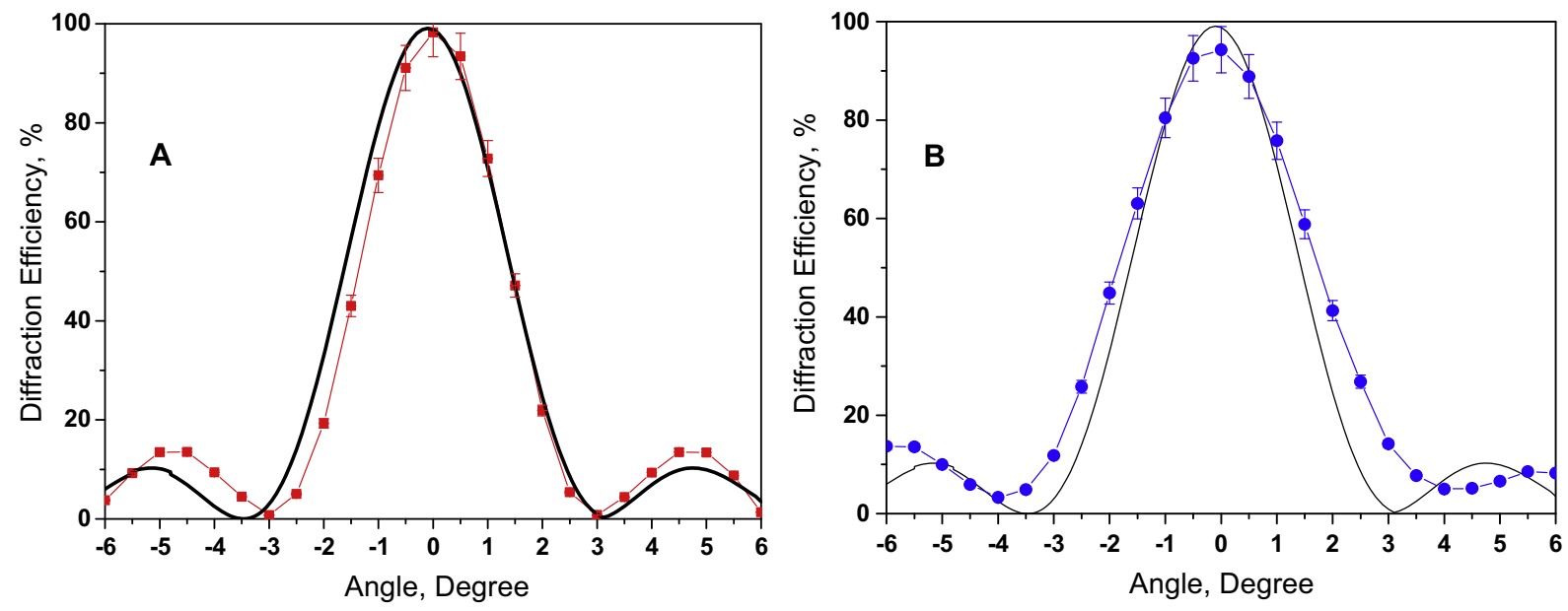

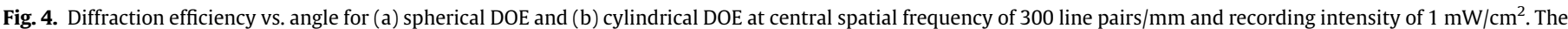
solid line is the theoretical curve for a 300 line pairs $/ \mathrm{mm}$ grating $50 \mu \mathrm{m}$ thick, probed with $633 \mathrm{~nm}$ light.

(Akbari et al., 2014b). Diffraction efficiency at Bragg incidence is over $95 \%$ (corrected for reflection at front and back surface).

\subsection{Variation of the diffraction efficiency with state of polarization of the probe beam}

The difference in efficiency for different polarizations can be also be modelled using Kogelnik Theory (Kogelnik, 1969) and has been previously exploited in order to make specific types of polarization-sensitive elements. For example, Habraken et al. presented theoretical and experimental results in Dichromated Gelatin demonstrating the possibility of making polarizers using plane diffraction gratings (Habraken et al., 1995). The dependence of the first order diffraction efficiency of volume phase holographic transmission grating on the polarization of the incoming light has also been discussed in detail by Baldry et al. (2004).
For unpolarized light the Kogelink Diffraction Efficiency is given by:

$\eta=\frac{1}{2} \sin ^{2}\left(\frac{\pi \Delta n^{2} d}{\lambda \cos \alpha}\right)+\frac{1}{2} \sin ^{2}\left(\frac{\pi \Delta n^{2} d}{\lambda \cos \alpha} \cos (2 \alpha)\right)$

Where the first term is for S-polarized light and the second term is for P-polarized light and $\Delta \mathrm{n}$ is refractive index modulation, $\mathrm{d}$ is the grating thickness and $\lambda$ is the wavelength of the reconstruction beam and $\alpha$ is defined as the angle between the incident beam and the grating fringes. As can be seen from the above equation, as small value for $\alpha$ should make the efficiency for the Ppolarized light approach that of the s polarized light.

$\alpha$ will be smaller for low spatial frequency fringes, so elements with lower spatial frequencies (having lower Bragg angles) are less sensitive to polarization direction. These low spatial frequency gratings were tested experimentally with two orthogonal polarization directions. Fig. 5 shows the dependence of first order diffrac- 


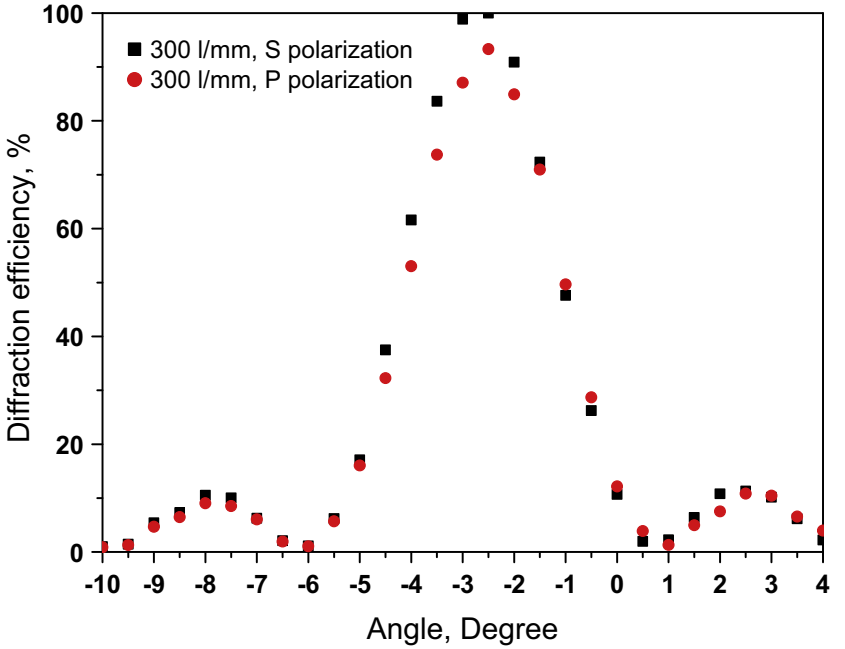

Fig. 5. Dependence of first order diffraction efficiency on grating thickness for spatial frequency of a 300 line pairs/mm grating for $\mathrm{S} \square$ and $\mathrm{P}$, polarization.

tion efficiency on the angle of incidence of the reading beam for $\mathrm{S}$ and P polarized light, for spatial frequency of 300 line pairs $/ \mathrm{mm}$. There is a difference in the peak Diffraction Efficiency of less than 5\%. This implies that the Diffraction Efficiency of these gratings (300 line pairs $/ \mathrm{mm}, 60 \mu \mathrm{m}$ thick) will be high in unpolarized light.

In order to test the element's performance with unpolarized light, the diffraction efficiency of the DOE was measured using a metal halide discharge lamp (Griven, GR0262) as a light source (Ahmed et al., 2016) with filters to isolate a wavelength of $633 \mathrm{~nm}$. A rotation stage was used to vary the angle of incidence and the diffraction efficiency of the diffracted beam was measured near to the focus point at range of angles. The results are shown in Fig. 6. A maximum diffraction efficiency of over $85 \%$ was observed at the Bragg angle, confirming that the DOEs perform well under unpolarized light.

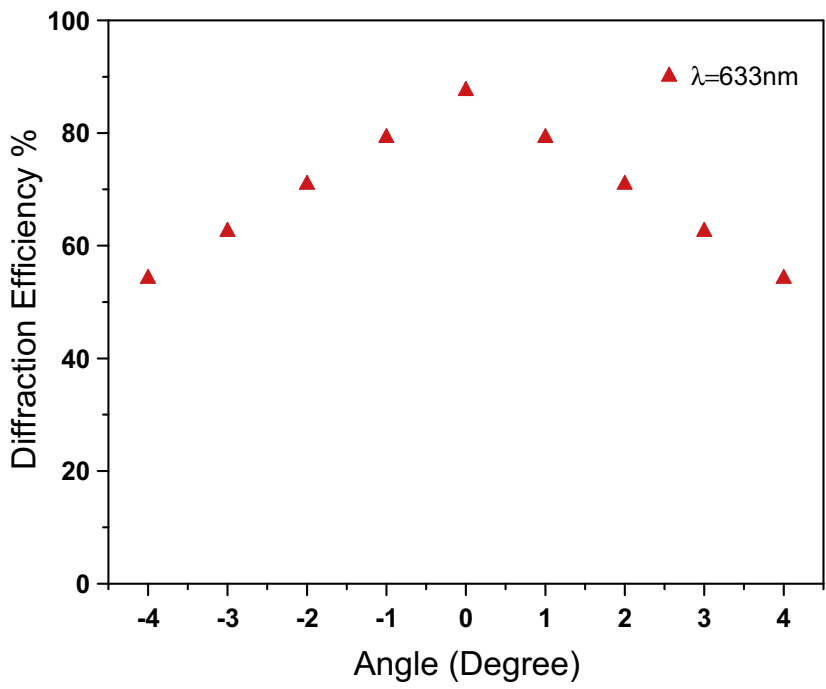

Fig. 6. Diffraction efficiency vs. angle using unpolarized red light from a solar simulator for a cylindrical DOEs.
3.3. Use of a multiplexed device to increase the concentration ratio of solar cells

The current vs applied voltages of the c-Si solar cell was measured using an electrical set up and the I-V curve was obtained (Fig. 7). In this study the area of the DOE was kept constant at $113 \mathrm{~mm}^{2}$. The short circuit current $\left(\mathrm{I}_{\mathrm{sc}}\right)$ output of the reference cell, i.e. without the DOE in place, was approximately $3.7 \pm 0.1 \mathrm{~mA}$. When a single cylindrical DOE was included, a relative increase in $I_{s c}$ of $16 \%$ was observed in comparison to the reference cell. When a single spherical DOE was included, an increase of $32 \%$ in signal was observed. This is a significant improvement, and is due to the fact that the light is focused in two dimensions instead of one. This measurement was then carried out for an array of two cylindrical and spherical DOEs, which resulted in an increase in the $\mathrm{I}_{\mathrm{sc}}$ of $40 \%$ and $78 \%$ respectively. These results suggest that the use of larger arrays of cylindrical and/or spherical DOEs can achieve higher relative increase in $\mathrm{I}_{\mathrm{sc}}$ for smaller areas of solar cells. The value for the short circuit current density $\left(\mathrm{J}_{\mathrm{sc}}\right)$ of the Si solar cell was estimated using the I-V curves data for spherical/cylindrical DOE and pairs of DOE relative to the solar cell area which in this case was $60 \mathrm{~mm}^{2}$. The results are presented in Table 1 .

Fig. 8 presents the relative increase in the $\mathrm{I}_{\mathrm{sc}}$ for the c-Si solar cells vs area of solar cells. The area of the DOE remained constant at $113 \mathrm{~mm}^{2}$ throughout the experiment whereas the solar cell area was varied between $9 \mathrm{~mm}^{2}$ and $100 \mathrm{~mm}^{2}$. In order to optimize the concentration ratio, the preference is to use solar cells significantly smaller than the DOEs. These results show that there is a significant improvement in the output current obtained when using the holographic focusing elements.

It has been observed that for solar cells with area of $9 \mathrm{~mm}^{2}$, a $52 \%$ increase in the output current is achieved for a single spherical DOE compared to $11 \%$ for $100 \mathrm{~mm}^{2}$ solar cell. This is because the smaller cell area makes better use of the focussing effect. A similar trend was achieved using a single cylindrical DOE; however, the concentration ratio was lower, as expected.

The relative increase was nearly double for an array of two cylindrical DOE compared to the single cylindrical DOE.

\section{Conclusions}

DOEs designed for effective operation under illumination with broadband unpolarised light were fabricated and tested with sili-

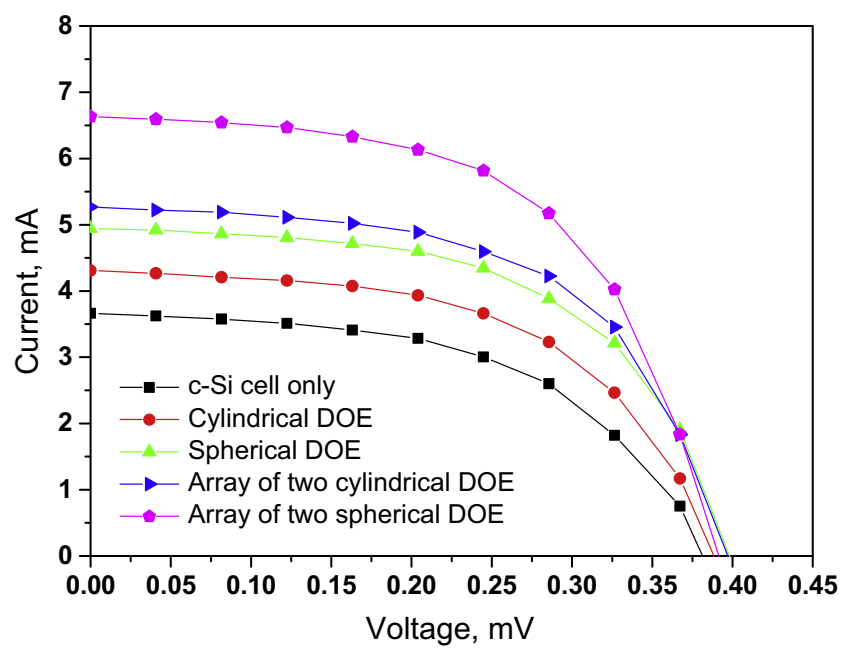

Fig. 7. I-V curves for a c-Si solar cell (Area $=60 \mathrm{~mm}^{2}$ ) without DOE, with cylindrical DOE, spherical DOE, array of two cylindrical DOE and array of two spherical DOE in place. 
Table 1

Calculated Jsc of the Si solar cell with range of DOE.

\begin{tabular}{|c|c|c|c|c|}
\hline & $\mathrm{I}_{\mathrm{sc}}\left(\mathrm{mA} / \mathrm{cm}^{2}\right)$ & $\Delta \mathrm{I}_{\mathrm{sc}}$ & $\begin{array}{l}\Delta \mathrm{I}_{\mathrm{sc}} \% \\
\pm 0.03\end{array}$ & $\mathrm{~J}_{\mathrm{sc}}\left(\mathrm{mA} / \mathrm{cm}^{2}\right)$ \\
\hline Bare Si & 3.7 & & & 0.061 \\
\hline With spherical DOE & 4.9 & 1.2 & 32 & 0.081 \\
\hline With cylindrical DOE & 4.3 & 0.6 & 16 & 0.071 \\
\hline Array of two spherical DOE & 6.6 & 2.9 & 78 & 0.110 \\
\hline Array of two cylindrical DOE & 5.2 & 1.5 & 40 & 0.086 \\
\hline
\end{tabular}

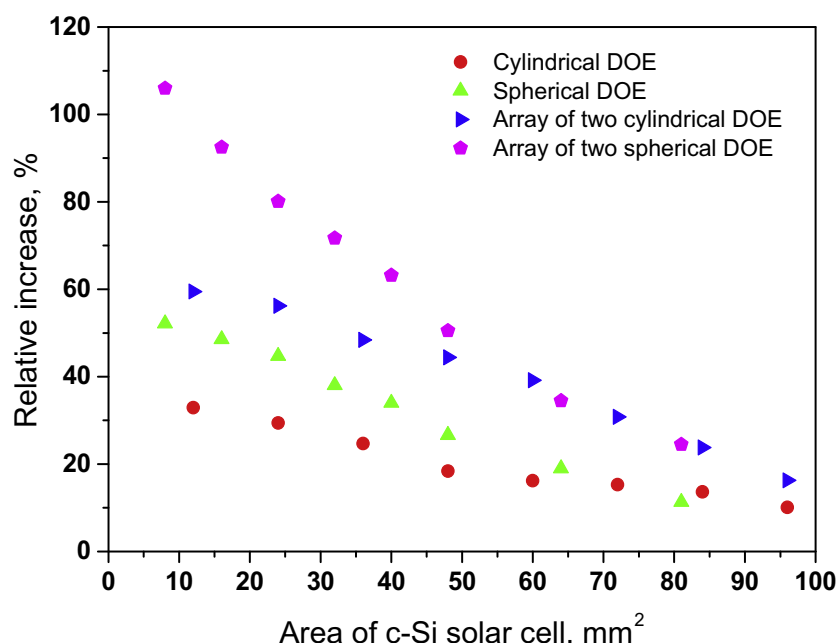

Fig. 8. The percentage increase of output current of c-Si solar cells vs. area of the cSi cells for spherical DOE, cylindrical DOE and arrays of two cylindrical and spherical DOEs.

con cells. Both cylindrical and spherical off-axis focusing DOEs were recorded with high efficiency. Focusing elements with low spatial frequency, broad working range and minimal sensitivity to the polarization state of the source were presented. Maximum diffraction efficiencies of $95 \%$ with laser illumination and $85 \%$ with an unpolarised source were observed in photopolymer layers of $50 \pm 5 \mu \mathrm{m}$ at spatial frequency of 300 line pairs $/ \mathrm{mm}$. The results for electrical characterization of the solar cells with the DOEs in place show that the DOEs can be beneficial for solar applications. The relative increase of the output current of c-Si solar cells was measured for cylindrical DOEs, spherical DOEs and pairs of two spherical and cylindrical DOEs to be approximately 16\%, 32\% and $40 \%$ respectively for a cell with an area of around $60 \mathrm{~mm}^{2}$. The results show that with a pair of DOEs designed to focus on the same position in place there is just over $100 \%$ increase in the short circuit current in the solar cell in the output current obtained for the solar cells with area of $12 \mathrm{~mm}^{2}$. This can be improved by increasing the number of DOEs in an array.

Future work will focus on fabrication of arrays of spherical DOE and multiplexing or staking to broaden the angular working range. This approach can be implementing in typical building integration and grading applications.

\section{Acknowledgments}

The authors would like to thank Dr. Dervil Cody, Dr. Subhash Chandra and Thomas Egan for very useful discussions. This work was partly supported by the School of Physics and the Dublin Institute of Technology Fiosraigh Postgraduate Scholarship Programme. The authors also acknowledge the FOCAS Institute for use of equipment and facilities at the Dublin Institute of Technology.

\section{References}

Ahmed, H., Doran, J., McCormack, S.J., 2016. Increased short-circuit current density and external quantum efficiency of silicon and dye sensitised solar cells through plasmonic luminescent down-shifting layers. Sol. Energy 126, 146-155. http:// dx.doi.org/10.1016/j.solener.2016.01.003.

Akbari, H., Naydenova, I., Martin, S., 2014a. Using acrylamide-based photopolymers for fabrication of holographic optical elements in solar energy applications. Appl. Opt. 53 (7), 1343-1353. http://dx.doi.org/10.1364/A0.53.001343.

Akbari, H., Naydenova, I., Persechini, L., Garner, S.M., Cimo, P., Martin, S., 2014b. Diffractive optical elements with a large angle of operation recorded in acrylamide based photopolymer on flexible substrates. Int. J. Polym. Sci. 918285

Altmeyer, S., Huey, Y., Thiée, P., Matrisch, J., Wallentin, M., Silbermann, J., 2013. Multiplexing of transmission holograms in photopolymer. DGaO Proceedings 2013. ISSN: 1614-8436 - urn:nbn:de:0287-2013-B009-9.

Arancibia-Bulnes, Camilo A., Peña-Cruz, Manuel I., Mutuberría, Amaia, Díaz-Uribe Rufino, Sánchez-González, Marcelino, 2017. A survey of methods for the evaluation of reflective solar concentrator optics. Renew. Sustain. Energy Rev. 69, 673-684.

Baldry, I.K., Bland Hawthorn, J., Robertson, J.G., 2004. Volume phase holographic gratings: polarization properties and diffraction efficiency. Publ. Astron. Soc. Pac. 116 (819), 403-414. http://dx.doi.org/10.1086/383622.

Bañares-Palacios, P., Álvarez-Álvarez, S., Marín-Sáez, J., Collados, M.-V., Chemisana, D., Atencia, J., 2015. Broadband behavior of transmission volume holographic optical elements for solar concentration. Opt. Exp. 23 (11), A671-A681. http:// dx.doi.org/10.1364/OE.23.00A671.

Barnham, K.W.J., Marques, J.L., Hassard, J., O’Brien, P., 2000. Quantum-dot concentrator and thermodynamic model for the global redshift. Appl. Phys. Lett. 76 (9), 1197-1199.

Belendez, A., Pascual, I.V., Fimia, A., 1991. Optimization of reconstruction geometry for maximum diffraction efficiency in HOE: the influence of recording material. In: Nowak, J., Zajac, M. (Eds.), Szklarska - DL Tentative. International Society for Optics and Photonics, pp. 77-83. http://dx.doi.org/10.1117/12.50126.

Bianco, G., Ferrara, M.A., Borbone, F., Roviello, A., Striano, V., Coppola, G., 2015 Photopolymer-based volume holographic optical elements: design and possible applications. J. Eur. Opt. Soc.: Rapid Publ. 10, 15057. http://dx.doi.org/ 10.2971/jeos.2015.15057.

Breitenbach, J., Rosenfeld, J.L., 2000. Goniospectrometer measurements of the optical performance of a holographic optical element. Sol. Energy 68 (5), 427437. http://dx.doi.org/10.1016/S0038-092X(00)00011-6.

Castro, J.M., Zhang, D., Myer, B., Kostuk, R.K., 2010. Energy collection efficiency of holographic planar solar concentrators. Appl. Opt. 49 (5), 858-870. http://dx. doi.org/10.1364/A0.49.000858 ->.

Chandra, S., McCormack, S.J., Kennedy, M., Doran, J., 2015. Quantum dot solar concentrator: optical transportation and doping concentration optimization. Sol. Energy 115, 552-561. http://dx.doi.org/10.1016/j.solener.2015.01.048.

Eames, P.C., Norton, B.N., 1977. Detailed parametric analyses of heat transfer in CPC solar energy collectors. Sol. Energy 50 (4), 321-338.

Fernández, E., Ortuño, M., Gallego, S., Márquez, A., García, C., Beléndez, A., Pascual, I. 2008. Multiplexed holographic data page storage on a polyvinyl alcohol/ acrylamide photopolymer memory. Appl. Opt. 47 (25), 4448-4456. http://dx. doi.org/10.1364/AO.47.004448.

Fimia, A., Carretero, L., Beléndez, A., 1994. Holographic optical elements recorded on spherical surfaces with photopolymers. Appl. Opt. 33 (17), 3633-3634. http:// dx.doi.org/10.1364/AO.33.003633.

Gallagher, S.J., Rowan, B.C., Doran, J., Norton, B., 2007. Quantum dot solar concentrator: device optimisation using spectroscopic techniques. Sol. Energy 81 (4), 540-547. http://dx.doi.org/10.1016/j.solener.2006.07.006.

Gallego, S., Márquez, A., Ḿndez, D., Neipp, C., Ortuño, M., Beĺndez, A., Ellipsis Pascual, I., 2008. Direct analysis of monomer diffusion times in polyvinyl/ acrylamide materials. Appl. Phys. Lett. 92 (7), 3-5. http://dx.doi.org/10.1063/ 1.2836948 .

Ghosh, A., Nirala, A.K., Yadav, H.L., 2015. Wavelength selective holographic concentrator: application to solar cells. Optik - Int. J. Light Electron Opt. http://dx.doi.org/10.1016/j.ijleo.2015.07.201.

Gleeson, M.R., Sabol, D., Liu, S., Close, C.E., Kelly, J.V., Sheridan, J.T., 2008 Improvement of the spatial frequency response of photopolymer materials by modifying polymer chain length. J. Opt. Soc. Am. B 25 (3), 396. http://dx.doi.org/ 10.1364/JOSAB.25.000396.

Goetzberger, A., Greubel, W., 1977. Solar energy conversion with fluorescent concentrators. Appl. Phys. 14, 123-139. 
Guntaka, S.R., Toal, V., Martin, S., 2002. Holographically recorded photopolymer diffractive optical element for holographic and electronic speckle-pattern interferometry. Appl. Opt. 41 (35), 7475-7479. http://dx.doi.org/10.1364/ AO.41.007475.

Habraken, S., Renotte, Y., Roose, S., Stijns, E., Lion, Y., 1995. Design for polarizing holographic optical elements. Appl. Opt. 34 (19), 3595-3602. http://dx.doi.org/ 10.1364/AO.34.003595.

Hsieh, M., Lin, S., Hsu, K.Y., Burr, J.A., Lin, S., 2011. An efficient solar concentrator using volume hologram. In: Conference on Lasers and Electro-Optics (CLEO), vol. 1, pp. 4-5.

Hung, J., Chan, P.S., Sun, C., Ho, C.W., Tam, W.Y., 2010. Doubly slanted layer structures in holographic gelatin emulsions: solar concentrators. J. Opt. 12 (4), 45104. http://dx.doi.org/10.1088/2040-8978/12/4/045104.

James, P.A.B., Bahaj, A.S., 2005. Smart glazing solutions to glare and solar gain: a "sick building" case study. Energy Build. 37 (10), 1058-1067. http://dx.doi.org/ 10.1016/j.enbuild.2004.12.010.

Jenney, J.A., 1970. Holographic recording with photopolymers. J. Opt. Soc. Am 60 (9), 1155. http://dx.doi.org/10.1364/JOSA.60.001155.

Kabeel, A.E., Abdelgaied, M., 2017. Observational study of modified solar still coupled with oil serpentine loop from cylindrical parabolic concentrator and phase changing material under basin. Sol. Energy 144, 71-78. http://dx.doi.org/ 10.1016/j.solener.2017.01.007.

Kennedy, M., McCormack, S.J., Doran, J., Norton, B., 2009. Improving the optical efficiency and concentration of a single-plate quantum dot solar concentrator using near infra-red emitting quantum dots. Sol. Energy 83 (7), 978-981. http:// dx.doi.org/10.1016/j.solener.2008.12.010.

Kogelnik, H., 1969. Coupled wave theory for thick hologram gratings. Bell Syst. Tech. J. 48 (9), 2909-2947. http://dx.doi.org/10.1002/j.1538-7305.1969.tb01198.x.

Kostuk, R.K., Castillo, J., Russo, J.M., Rosenberg, G., 2007. Spectral-shifting and holographic planar concentrators for use with photovoltaic solar cells. Proc. SPIE 6649. http://dx.doi.org/10.1117/12.736542. 66490I-66490I-8.

Kostuk, R.K., Rosenberg, G., 2008. Analysis and design of holographic solar concentrators. Proc SPIE 70430I. http://dx.doi.org/10.1117/12.793895.

Kostuk, R.K., Castro, J., Zhang, D., Dimroth, F., Kurtz, S., Sala, G., Bett, A.W., 2011. Energy yield analysis of tracking and non-tracking holographic planar concentrators. AIP Conference Proceedings, vol. 1407. American Institute of Physics, pp. 137-140. http://dx.doi.org/10.1063/1.3658312.

Mallick, T., Shanks, K., Senthilarasu, S., 2015. Optics for concentrating photovoltaics: trends limits and opportunities for materials and design. Renew. Sustain. Energy Rev. 60, 394-407.

Martin, S., Feely, C.A., Sheridan, J.T., Toal, V., 1998. Applications of a self-developing photopolymer material: holographic interferometry and high-efficiency diffractive optical elements. In: Trout, T.J. (Ed.), Photonics West '98 Electronic Imaging. International Society for Optics and Photonics, pp. 60-70. http://dx. doi.org/10.1117/12.304530.
Mohan, N.K., Islam, Q.T., 2006. Design of an off-axis HOE light concentrator to focus light from multiple directions in a plane. Opt. Lasers Eng. 44 (9), 943-953. http://dx.doi.org/10.1016/j.optlaseng.2005.06.019.

Naydenova, I., Akbari, H., Dalton, C., Pang, C., Wei, T., Toal, V., 2013. Photopolymer holographic optical elements for application in solar energy concentrators. In: Holography - Basic Principles and Contemporary Applications. http://dx.doi. org/10.5772/55109.

Norton, B., Eames, P., Mallick, T., Huang, M., McCormack, S., Mondol, J., 2011. Enhancing the performance of building integrated photovoltaics. Sol. Energy 85, 1629-1664.

Rabl, A., 1976. Comparison of solar concentrators. Sol. Energy 18, 93-111.

Reisfeld, R., Eyal, M., Chernyak, V., Zusman, R., 1988. Luminescent solar concentrators based on thin films of polymethlmethacrylate on a polymethlmethacrylate support. Sol. Energy Mater. 17, 439-455.

Sam, S.T.L., Kumar, A.P.T., Predeep, P., Thakur, M., Varma, M.K.R., 2011. Design and Optimization of Photopolymer Based Holographic Solar Concentrators, vol. 248, pp. 248-250. http://dx.doi.org/10.1063/1.3646844.

Shakher, C., Yadav, H.L., 2000. Dependence of diffraction efficiency of holographic concentrators on angle of illumination, hologram-thickness and wavelength of illuminating light. J. Opt. 21 (6), 267-272. http://dx.doi.org/10.1088/0150536X/21/6/005.

Singh, D.B., Tiwari, G.N., 2017. Performance analysis of basin type solar stills integrated with identical photovoltaic thermal (PVT) compound parabolic concentrator (CPC) collectors: a comparative study. Sol. Energy 142, 144-158.

Sreebha, A.B., Mahadevan Pillai, V.P., Kumar, P.T., 2015. Development of a window holographic lens to utilize solar energy, advances in optical science and engineering. In: Lakshminarayanan, V., Bhattacharya, I. (Eds.), vol. 166, Springer India, New Delhi. http://dx.doi.org/10.1007/978-81-322-2367-2.

Srivastava, A., Sawant, S.M., Mainali, L., Bhatt, R., Gupta, A.K., Samui, A.B., 2012 Polyvinyl alcohol/acrylamide based photopolymer composition as recording medium for high-resolution volume-phase holograms. Polym. Adv. Technol. 23 (6), 967-974. http://dx.doi.org/10.1002/pat.1999.

Tarjányi, N., Tarjányi, N., Káčik, D., Káčik, D., Sabol, D., Sabol, D., Ellipsis Sheridan, J. T., 2009. Low spatial frequency grating recorded in photopolymer material. Advances 7358, 1-12. http://dx.doi.org/10.1117/12.829135.

Winston, R., Hinterberger, H., 1975. Principles of cylindrical concentrators for solar energy. Sol. Energy. http://dx.doi.org/10.1016/0038-092X(75)90007-9.

Wisam, A.M., Al-Shohani, Al-Dadah, Raya, Mahmoud, Saad, Algareu, Abdulmaged, 2016. Optimum design of V-trough concentrator for photovoltaic applications. Sol. Energy 140, 241-254.

Xie, W.T., Dai, Y.J., Wang, R.Z., Sumathy, K., 2011. Concentrated solar energy applications using Fresnel lenses: a review. Renew. Sustain. Energy Rev. 15 (6), 2588-2606.

Xu, Ning, Ji, Jie, Sun, Wei, Huang, Wenzhu, Li, Jing, Jin, Zhuling, 2016. Numerical simulation and experimental validation of a high concentration photovoltaic/ thermal module based on point-focus Fresnel lens. Appl. Energy 168, 269-281. 